\title{
Combination Twist1 and CA15-3 in axillary lymph nodes for breast cancer prognosis
}

\author{
XIAOWEI JIANG ${ }^{1,2^{*}}$, DAN GUO $^{3}$, WENFANG LI ${ }^{1,2}$, TIANWU YU ${ }^{4}$, JIAN ZHOU ${ }^{4}$ and JIANPING GONG ${ }^{1,2^{*}}$ \\ Departments of ${ }^{1}$ Hepatobiliary Surgery, ${ }^{2}$ General Surgery and ${ }^{3}$ Breast Gland Surgery, \\ The Second Affiliated Hospital of Chongqing Medical University, Chongqing 400010; ${ }^{4}$ Department of General Surgery, \\ Affiliated Yong Chuan Hospital of Chongqing Medical University, Chongqing 402160, P.R. China
}

Received December 11, 2015; Accepted December 2, 2016

DOI: $10.3892 / \mathrm{mmr} .2017 .6138$

\begin{abstract}
Twist1 overexpression is involved in epithelial-mesenchymal transition resulting in migration and metastasis of breast cancer. Carcinoma antigen 15-3 (CA15-3) is widely used to monitor the prognosis for patients after treatment. However, the significance of Twist1 in axillary lymph nodes (ALN) and CA15-3 for co-examination for survival rates remains to be elucidated. The present study aimed to explore the role of the combination of Twist1 expression in metastasized ALN and the serum level of CA15-3 in evaluating the prognosis of patients with breast cancer. cluster of differentiation (CD)44, CD24, aldehyde dehydrogenase (ALDH)1 and Twist1 expression in normal and metastasized ALN from 102 patients with breast cancer were detected using laser confocal microscopy and the expression of the genes evaluated by reverse transcription-quantitative polymerase chain reaction; E-cadherin, $\mathrm{N}$-cadherin and vimentin expression was also tested by western blotting. The serum concentrations of CA15-3 prior to and following surgery were analyzed by chemiluminescence immunoassay. The expression of CD44, ALDH1 and Twist1 mRNA in the primary breast cancer tissues and involved ALN was upregulated compared with the normal ALN $(\mathrm{P}<0.05)$. The proteins $\mathrm{N}$-cadherin and vimentin of the involved ALN were poorly expressed compared with breast cancer tissues, however E-cadherin protein expression was higher in metastasized and normal ALN compared with primary cancer tissues $(\mathrm{P}<0.05)$. Of the 102 patients, the serum CA15-3 levels of the patients in stages I and II were significantly lower compared with stages III and IV $(\mathrm{P}<0.05)$.
\end{abstract}

Correspondence to: Dr Jianping Gong, Department of Hepatobiliary Surgery, The Second Affiliated Hospital of Chongqing Medical University, 74 Linjiang Road, Chongqing 400010, P.R. China

E-mail: 674079699@qq.com

${ }^{*}$ Contributed equally

Key words: breast cancer stem cells, Twist1, carcinoma antigen 15-3, co-examination, prognosis
Twist $1^{+} / \mathrm{CA} 15-3^{+}, \mathrm{HER} 2-$ negative/Twist $1^{+} / \mathrm{CA} 15-3^{+}$and Triple-receptor negative/Twist $1^{+} / \mathrm{CA} 15-3^{+}$groups displayed a shorter progression-free survival compared with others. The results of the present study demonstrated that CD44, ALDH1 and Twist1 were significantly overexpressed in involved ALN. The serum levels of CA15-3 in those patients were clearly increased and the survival rates decreased, which suggested that a combination of Twist1 in ALN and CA15-3 may function as an indicator for the prognosis of patients with breast cancer.

\section{Introduction}

Identification of breast cancer stem cells (BCSCs) from tumor samples or breast cancer cell lines has been based primarily on cluster of differentiation (CD) $44^{+} / \mathrm{CD} 24^{-/ \text {low }}$ or aldehyde dehydrogenase $(\mathrm{ALDH})^{+}$phenotypes (1). Due to their invasiveness, resistance to chemo- and radiotherapy, mesenchymal phenotype and hypothesized role in seeding distant metastases, agents that specifically target the population of breast cancer cells bearing the $\mathrm{CD} 44^{\text {pos }} \mathrm{CD} 24^{\text {neg/low }}$ cell surface phenotype, which was first described by Vazquez-Martin et al (2) as a cardinal feature of BCSCs, are required. However, it is well-known that, in addition to CD44 expression, the expression of ALDH1 and Twist1 is involved in breast cancer invasion, metastasis and relapse. ALDH1 is a marker of normal and malignant human mammary stem cells and a predictor of poor clinical outcome (3). A previous study (4) reported that the overexpression of Twist1 can promote upregulation of ALDH1. The basic helix-loop-helix transcription factor Twist1 was previously demonstrated (5) to be a potent promoter of both cancer cell dissemination into circulation and metastases, providing a promising therapeutic target for intervention (6). Twist1 can activate a latent process termed the epithelial-mesenchymal transition (EMT), thus enabling carcinoma cells to dissociate from each other and migrate (7). For epithelial malignancies, EMT is a crucial event in the dissemination of cancer cells (8). Further understanding of the mechanisms by which Twist 1 promotes metastasis and the identification of Twist1 functional modulators may hold promise for developing novel strategies to inhibit EMT and cancer metastases (9). Currently, lymph node metastases (LNM) are considered to be a manifestation of widespread metastatic process and more useful markers of an aggressive 
primary tumor (PT) compared with the 'bridgeheads' for predicting further metastatic spread (10). LNM are enriched in cells with more aggressive phenotypes, marked by elevated levels of EMT regulators (11). Experimental models provide further evidence that the development of LNM indicates the increased potential of PT to disseminate aggressive cells and produce metastasis-promoting growth factors (10). Thus, molecular profiling of LNM may be used as a surrogate marker for the aggressiveness and metastatic potential of PT (11). At present, a variety of biological tumor markers are studied to diagnose these early diseases, monitor recurrence or metastasis in treated patients and to predict response or resistance to therapies (7). Carcinoma antigen 15-3 (CA15-3) is a member of a polymorphous group of highly glycosylated proteins $(12,13)$ and is the most widely-applied serum marker due to the fact that it is easy to use, cheap and quick to use. CA15-3 is particularly useful for tracking treatment in those patients who cannot be assessed by radiology. Due to the lack of specificity, measurement of CA15-3 serum levels alone is not suitable for the follow-up of patients with breast cancer. However, at present, CA15-3, carcinoembryonic antigen (CEA) and others are primarily utilized to monitor therapy in metastatic breast cancer in combination with imaging, history and physical examination (14).

Therefore, the present study assumed that targeting LNM and a combination of Twistland CA15-3 levels were significant for prognosis of breast cancer because Twist1 served a vital role in promoting tumor cell metastasis and recurrence.

\section{Materials and methods}

Reagents. Allophycocyanin (APC)-conjugated rabbit anti-human CD24 (catalogue no. sc-11406 FL-80) and rabbit anti-human Twist1 (catalogue no. sc-15393 H-81) antibodies were obtained from Santa Cruz Biotechnology, Inc. (Santa Cruz, CA, USA). Rabbit anti-human CD44 (catalogue no. GTX 102111) was obtained from GeneTex, Inc. (Irvine, CA, USA). ALDH1 (catalogue no. ab52492) was obtained from Abcam, Shanghai, China. The donkey anti-rabbit IgG-fluorescein isothiocyanate (FITC) antibodies (catalogue no: SA00003-8) and goat anti-rabbit phycoerythin (PE) antibodies (catalogue no: SA00008-2) were from Wuhan Sanying Biotechnology, Wuhan, China. The rabbit anti-histone H3 antibody (catalogue no. ZDR-5105) was from Beijing Zhongshan Jinqiao Biotechnology Co., Ltd (Beijing, China). Vimentin (catalogue no: CST 5741P D21H3) and N-cadherin (catalogue no: CST13116p) antibodies were from Cell Signaling Technologies, Inc. (Danvers, MA, USA). The primer synthesis, reverse transcription-quantitative polymerase chain reaction (RT-qPCR) kit (catalogue no. RP1202) and western blotting kits were provided by Takara Biotechnology Co., Ltd., (Dalian, China). 4',6-diamidino-2-phenylindole (DAPI) was purchased from Molecular Probes, Inc. (Thermo Fisher Scientific, Inc., Waltham, MA, USA). The X-ray film for autoradiography was from Kodak (Rochester, NY, USA). The chemiluminescence immunoassay kit was purchased from Roche Diagnostics (Indianapolis, IN, USA). The hematoxylin and eosin (H\&E) staining kit was from Shanghai Shenggong Biology Engineering Technology Service, Ltd. (Shanghai, China).
Ethics statement. Research specimens were collected from surgically removed tumor tissues and the clinicopathological data were obtained after the selected patients signed informed consent forms. These forms allowed the use of the biological tissues for research purposes. All protocols were approved by the Ethics Committee of Affiliated Yong Chuan Hospital of Chongqing Medical University (Chongqing, China).

Tissue specimens. A total of 102 patients with primary breast cancer underwent definitive surgery from 2007 to 2014 at the Department of Breast Gland Surgery in The Second Affiliated Hospital of Chongqing Medical University (Chongqing, China). All patients were Chinese females aged 38-69 years old. Availability of PT and matched LNM was mandatory. Patients with no evidence of lymph node involvement or earlier chemotherapy were deemed ineligible for the present study. Non-cancer control breast tissue samples were acquired during mastectomy. Patient survival data was collected at this stage; information on patients included age, tumor size, nodal status, tumor grade, histological tumor type, and ER, PR and human epidermal growth factor receptor 2 (HER2) status, was obtained from the Department of Breast Gland Surgery and Pathology of the hospital. HER2 expression status was scored with MoAb clone CB11, a monoclonal antibody (Novocastra; Leica Biosystems, Newcastle Ltd., Newcastle, UK). The data treated by immunohistochemistry were collected from Department of Pathology, The Second Affiliated Hospital of Chongqing Medical University. The tumor tissues were immediately frozen following removal and stored at $-80^{\circ} \mathrm{C}$ in liquid nitrogen. Finally, total RNA and protein were isolated from frozen tumor tissues using TRizol reagent or DAPI NP-40 lysis buffer, respectively. All specimens were stored in a $-80^{\circ} \mathrm{C}$ freezer (Invitrogen; Thermo Fisher Scientific, Inc.).

Immunofluorescence and laser confocal scanning analysis. Laser confocal scanning analysis was performed as described previously (15). Sections of human breast gland and ALN tissues were first identified to be breast cancer and matched ALN metastases with H\&E staining. The sample slides were then treated by immunofluorescence staining. After a wash in $0.01 \mathrm{M} / 1$ phosphate-buffered saline (PBS; $\mathrm{pH} 7.4$ ), the samples were incubated with a blocking buffer (1\% bovine serum albumin, 5\% normal goat serum and $0.1 \%$ Triton X-100-PBS) for $1 \mathrm{~h}$ at room temperature. Samples were then incubated with primary rabbit anti-human antibodies (CD44, CD24, Twist1 and ALDH1; 1:200 dilution) and diluted in the blocking buffer at $4^{\circ} \mathrm{C}$ overnight in a humidified chamber, followed by three washes in PBS for 15 min each. The samples were then stained with secondary antibodies (donkey anti-rabbit IgG-FITC antibodies for the CD44 and ALDH1 sections, and goat anti-rabbit PE antibodies for the CD24 and Twist1 sections; 1:2,000 dilution) diluted in blocking buffer for $30 \mathrm{~min}$, followed by three washes in PBS. Coverslips were mounted on slides with DAPI (ProLong ${ }^{\circledR}$ Gold antifade reagent; Molecular Probes, Inc.; Thermo Fisher Scientific, Inc.). Positive control slides were run simultaneously to assess the quality of immunoreactivity. Normal ALN (30 mm away from the cancer tissue) were used as negative controls. Finally, immunostained tissues were visualized and imaged using an inverted optical microscope and an inverted fluorescence confocal microscope. 
Total RNA extraction from fresh-frozen tissue. The tissue samples stored at $-80^{\circ} \mathrm{C}$ were thawed and immediately treated. Tissue sections of 20-30 mg were homogenized with zircon beads in a MagNA Lyzer (Roche Diagnostics $\mathrm{GmbH}$, Mannheim, Germany) for $40 \mathrm{sec}$. Total RNA was isolated using the RNeasy Mini kit (Takara Biotechnology Co., Ltd) according to the manufacturer's protocol, including on-column DNase I treatment.

RNA analysis and reverse transcription. To determine the gene expression of CD44, CD24, ALDH1 and Twist1 in the specimens obtained from the surgery, followed by the reverse transcription of RNA, sequences of the human primers (provided by Takara Biotechnology Co., Ltd.) were designed as follows: CD44, 5'GCCCAATGCCTTTGATGG ACC3' (sense primer), 3'GCAGGGATTCTGTCTGTGCTG5' (anti-sense primer); CD24, 5'-ATGGGCAGAGCAATGGTG GCCA-3' (sense primer) and 3'TCAAGAGAAGCACCA GAGTGAGA5' (anti-sense primer); Twist1, 5'CAAGAAGTC TGCGGGCTGTG3' (sense primer), 5'TCGTTCAGCGAC TGGGTGC3' (anti-sense primer); ALDH1, 5'CAAACGACC ATCTGCCGCT3' (sense primer), 5'CAGGTTGCCTCTCAC TCGGTT3' (anti-sense primer). For all samples, the RNA concentration and purity were determined using a Nano-Drop ND-1000 spectrophotometer (Thermo Fisher Scientific, Inc.). Qualitative analysis of the RNA was performed by microcapillary electrophoresis using the Agilent 2100 Bioanalyzer with Expert Software, version B.02.08 using an RNA Nano Chip (Agilent Technologies, Inc., Santa Clara, CA, USA). For each sample, whenever possible, $1 \mu \mathrm{g}$ RNA was used as the template in the reverse transcription reaction using the Transcriptor First Strand cDNA Synthesis kit (Roche Diagnostics GmbH) in a $20 \mu \mathrm{l}$ volume with random hexamer primers according to the manufacturer's protocol. Total PCR was processed for 35 cycles $\left(95^{\circ} \mathrm{C}, 30 \mathrm{sec} ; 56^{\circ} \mathrm{C}, 30 \mathrm{sec} ; 72^{\circ} \mathrm{C}, 15 \mathrm{sec}\right)$ with $\mathrm{Taq}$ DNA polymerase (Invitrogen; Thermo Fisher Scientific, Inc.). Relative mRNA levels were quantified using SYBR supermix (Bio-Rad Laboratories, Inc., Hercules, CA, USA) on an iCycler iQ5 for 40 cycles $\left(95^{\circ} \mathrm{C}, 30 \mathrm{sec} ; 54^{\circ} \mathrm{C}, 20 \mathrm{sec} ; 72^{\circ} \mathrm{C}, 15 \mathrm{sec}\right)$ followed by default melting curve cycles, and IQ5 software for PCR baseline subtraction (Bio-Rad laboratories, Inc.) was used for analysis.

Fresh-frozen tissue for western blot analysis. For western blot analysis, the tissue samples stored at $-80^{\circ} \mathrm{C}$ were quickly thawed and treated immediately. Whole cell lysates were prepared from the frozen tissues. Briefly, following centrifugation at $800-1000 \times \mathrm{g}, 4^{\circ} \mathrm{C}$ for $3 \mathrm{~min}$, the samples were collected by centrifugation and resuspended in $100 \mu \mathrm{M}$ SDS sample buffer [125 mM Tris-HCl, pH 6.8, 20\% (v/v) glycerol, 2\% (w/v) SDS, $0.2 \%(\mathrm{w} / \mathrm{v})$ bromophenol blue] prior to boiling for $5 \mathrm{~min}$. Subsequently, $30 \mu \mathrm{g}$ protein from each lysate was loaded onto $12 \%$ SDS polyacrylamide gels, separated by electrophoresis and transferred onto a nitrocellulose membrane prior to probing with rabbit anti-vimentin and $\mathrm{N}$-cadherin $(1: 2,000)$ at $4^{\circ} \mathrm{C}$ overnight. The horseradish peroxidase-conjugated anti-rabbit secondary antibody (1:1,000, catalogue no. ab6721, Abcam) was detected using the ECL Advanced Western Blotting kit (Takara Biotechnology Co., Ltd.) and visualized using the Molecular Imager ChemiDoc XRS System (Bio-Rad
Laboratories, Inc., Hercules, CA, USA). Lysates were probed with rabbit anti-histone $\mathrm{H} 3$ antibody $(1: 2,500)$ as a loading control.

Tumor markers. In addition, $2 \mathrm{ml}$ peripheral venous blood was collected from each of the studied patients on the 4th day prior to and the 3rd day following surgery respectively. This blood was used to detect the serum CA15-3 levels, which are currently considered useful tumor markers for breast cancer. Serum CA15-3 concentrations were determined by chemiluminescence immunoassay using a commercially available kit (Roche Diagnostics), and the cut-off level recommended by the manufacturers was $30 \mathrm{U} / \mathrm{ml}$. The within- and between-assay coefficients of variation for CA15-3 were $<9 \%$. Finally, the blood samples of the 102 patients were divided into four groups: The stages I and II group, the stages III and IV group, the pre-operative group and the post-operative group. The increase in tumor markers was considered progressive when it was $>30 \%$ in the sample following the initial elevated value.

Statistical analysis. Statistical analyses of the results were performed in Microsoft Excel 2007 (Microsoft Corporation, Redmond, WA, USA) and SPSS software, version 15.0.1 (SPSS, Inc., Chicago, IL, USA) and expressed as the mean \pm standard deviation. Student's $t$-test was used for paired comparisons between the data groups. A two-way analysis of variance test was then conducted using the defining factors comparison, among the multi-data groups and for nonparametric tests. $\mathrm{P}<0.05$ was considered to indicate a statistically significant difference.

The patients were continuously followed-up for 6 years and 184 days after leaving the hospital. Progression-free survival (PFS) was defined as the time from the first diagnosis of breast cancer until the radiographical examination of progression. Patient mortality without progressive evidence were treated as events and the patients who were lost to follow-up were treated as censored observations. The overall survival rate was defined as the time from endocrine therapy until the mortality date or the most recent follow-up. The median PFS and median survival time were calculated using the Kaplan-Meier method, and marked statistical differences in survival curves were examined using the log-rank test.

\section{Results}

The clinicopathological data from the patients in the current study are presented in Table I. A selected series of 102 primary invasive breast carcinomas were included in the present study. All histological sections of tumor specimens were re-evaluated by two experienced pathologists. Each patient was staged according to the International Union Against Cancer TNM classification (16). The tumor size was $\leq 2 \mathrm{~cm}$ in $35.7 \%(n=45)$ of cases and $>2 \mathrm{~cm}$ in $64.3 \%(n=57)$ of cases. Pathological examination revealed that the status of all ALN was positive. Histological grading was performed according to the Elston and Ellis method (17) and 45.1\% ( $=46)$ of tumors were histological grade $1-2$ and $54.9 \%(n=56)$ were grade 3 . In addition, of all of the tumors $75(73.8 \%)$ were invasive ductal carcinoma not otherwise specified, with the remaining $27(26.2 \%)$ consisting of other histological types, including 
Table I. Clinicopathological data for the patients in the present study; median (range) age 53.5 (41-71) years old.

\begin{tabular}{|c|c|c|}
\hline Variable & $\begin{array}{l}\text { Number of cases } \\
\qquad(n=102)\end{array}$ & $\%$ \\
\hline \multicolumn{3}{|c|}{ Tumor stage } \\
\hline $\mathrm{T} 1-2$ & 29 & 28.5 \\
\hline T3-4 & 73 & 71.5 \\
\hline \multicolumn{3}{|c|}{ Nodes stage } \\
\hline N1 & 26 & 25.4 \\
\hline N2 & 62 & 60.7 \\
\hline N3 & 14 & 13.9 \\
\hline \multicolumn{3}{|l|}{ ER status } \\
\hline Negative & 36 & 35.3 \\
\hline Positive & 66 & 64.7 \\
\hline \multicolumn{3}{|l|}{ PR status } \\
\hline Negative & 72 & 70.5 \\
\hline Positive & 30 & 29.5 \\
\hline \multicolumn{3}{|c|}{ HER2 status } \\
\hline Negative & 77 & 75 \\
\hline Positive & 33 & 24.5 \\
\hline \multicolumn{3}{|c|}{ Histological type } \\
\hline Ductal & 61 & 59.8 \\
\hline Lobular & 22 & 21. \\
\hline Other & 19 & 18. \\
\hline \multicolumn{3}{|c|}{ Tumor grade } \\
\hline G1-2 & 66 & 64.7 \\
\hline G3 & 36 & 35.2 \\
\hline \multicolumn{3}{|c|}{ BCA225 antigen } \\
\hline$>75 \mu \mathrm{g} / 1$ & 69 & 67. \\
\hline$<75 \mu \mathrm{g} / 1$ & 63 & 32. \\
\hline \multicolumn{3}{|c|}{ Serum CEA level } \\
\hline$>7 \mathrm{ng} / \mathrm{l}$ & 73 & 71. \\
\hline
\end{tabular}

ER, estrogen receptor; PR, progesterone receptor; HER2, human epidermal growth factor receptor 2; CEA, carcinoembryonic antigen.

medullary and lobular tumors. The variables collected for the expression analysis were estrogen receptor (ER) and progesterone receptor (PR) status, human epidermal growth factor receptor 2 (HER2) status and BCA225 antigen status. ER and PR were considered to be overexpressed when $>10 \%$ of the nuclei were positive. The HER2 status was scored as $0,1^{+}, 2^{+}$ or $3^{+}$. In accordance with the Dako HercepTest scoring system; 0 , no membranous immunoreactivity or $<10 \%$ of cells reactive; $1^{+}$, incomplete membranous reactivity in $>10 \%$ of cells; $2^{+},>0 \%$ of cells with weak to moderate complete membranous reactivity; and $3^{+}$, strong and complete membranous reactivity in $>10 \%$ of cells. It was noted that 32 of the 102 patients demonstrated the BCA225 antigen $>75 \mu \mathrm{g} / 1$ in their blood and the serum CEA level of $76.5 \%$ (78/102) patients was $>7 \mathrm{ng} / \mathrm{l}$.

The median follow-up calculated by the Kaplan-Meier method was 5 years and 224 days. The median follow-up of patients who did not have an event $(n=33)$ was 5 years and

\section{A Primary breast cancer tissue}

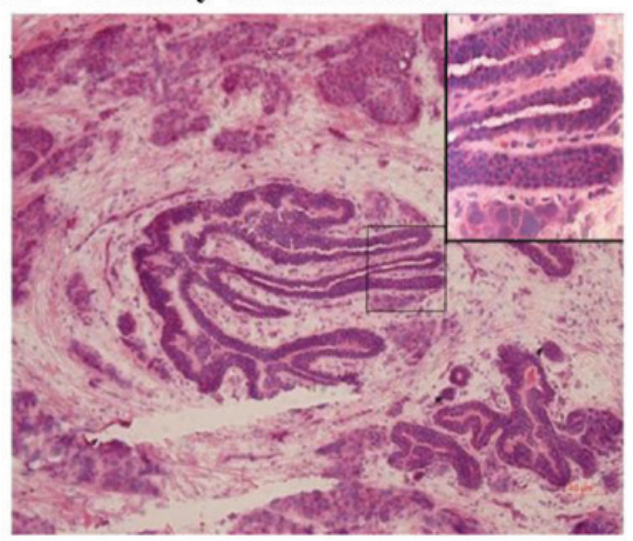

B Involved axillary lymph node

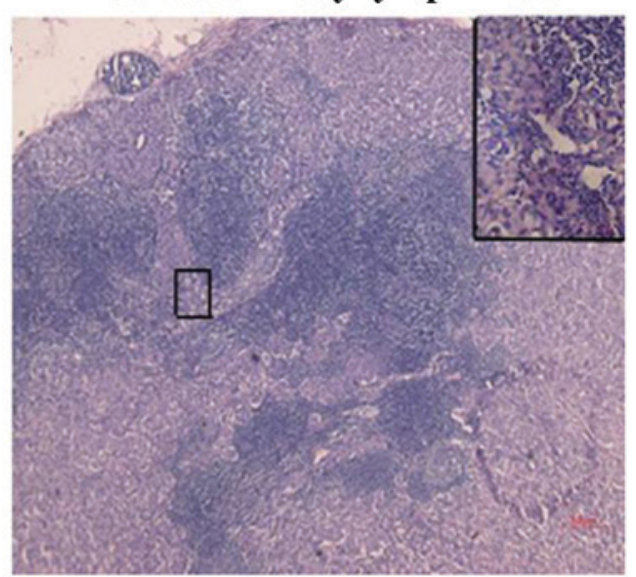

Figure 1. Breast cancer tissues and involved ALN demonstrated by H\&E staining. (A) Breast gland cancer tissues were confirmed by H\&E staining (original magnification, x100; inset, x400). (B) The sections of involved ALN were confirmed to be metastatic breast cancer cells by H\&E staining (original magnification, x100; inset, x400). ALN, axillary lymph nodes; $\mathrm{H} \& \mathrm{E}$, hematoxylin and eosin.

317 days. Those exhibiting local and regional relapse and died from tumors) were 3 years and 327 days $(n=69)$. The average number of metastatic lymph nodes was 4.8 (range 1-22).

Expression of CD44 markedly increased in PT and lymph node metastasis compared with normal lymph nodes. To investigate whether BCSCs were present in the collected specimens (the breast gland tissues, normal ALN and involved ALN), the expression levels of CD44 and CD24 were determined by immunofluorescence staining and laser confocal microscope analysis with rabbit anti-human CD44 and CD24 antibodies, respectively. All slide sections, including breast cancer tissues (Fig. 1A) and involved ALN (Fig. 1B), were first verified by H\&E staining. The results of immunofluorescence staining demonstrated that CD44 and CD24 were all expressed at low levels in the normal ALN (Fig. 2A; CD44 conjugated-FITC and CD24 conjugated-PE). However, CD44 was strongly localized on the membranes of the tumor cells and existed as an intercellular substance slightly distinct from the breast cancer tissues and the involved ALN (Fig. 2A, CD44 conjugated-FITC and CD24 conjugated-PE). The results demonstrated that CD44 was 
Table II. Overexpression of genes in the primary breast cancer tissue and ALN.

\begin{tabular}{|c|c|c|c|c|c|c|c|c|}
\hline \multirow[b]{2}{*}{ Variable } & \multicolumn{2}{|c|}{$\begin{array}{l}\text { Normal ALN-low } \\
\text { expression }\end{array}$} & \multicolumn{3}{|c|}{$\begin{array}{c}\text { Primary } \\
\text { tissue-overexpression }\end{array}$} & \multicolumn{3}{|c|}{$\begin{array}{c}\text { Involved } \\
\text { ALN-overexpression }\end{array}$} \\
\hline & $\mathrm{n}$ & $\%$ & $\mathrm{n}$ & $\%$ & P-value & $\mathrm{n}$ & $\%$ & P-value \\
\hline CD44 & $75 / 102$ & 73.5 & $89 / 102$ & 87.3 & $<0.05$ & $84 / 102$ & 82.4 & $<0.05$ \\
\hline CD24 & $6 / 102$ & 5.9 & $3 / 102$ & 3.9 & $>0.05$ & $2 / 102$ & 1.9 & $>0.05$ \\
\hline ALDH1 & $52 / 102$ & 51 & 78/102 & 76.5 & $<0.05$ & $87 / 102$ & 85.3 & $<0.05$ \\
\hline Twist1 & $54 / 102$ & 52.9 & $82 / 102$ & 80.4 & $<0.05$ & $71 / 102$ & 69.6 & $<0.05$ \\
\hline
\end{tabular}

Primary cancer tissue vs. normal ALN, involved lymph node vs. normal ALN. ALN, axillary lymph nodes; CD, cluster of differentiation; ALDH, aldehyde dehydrogenase.
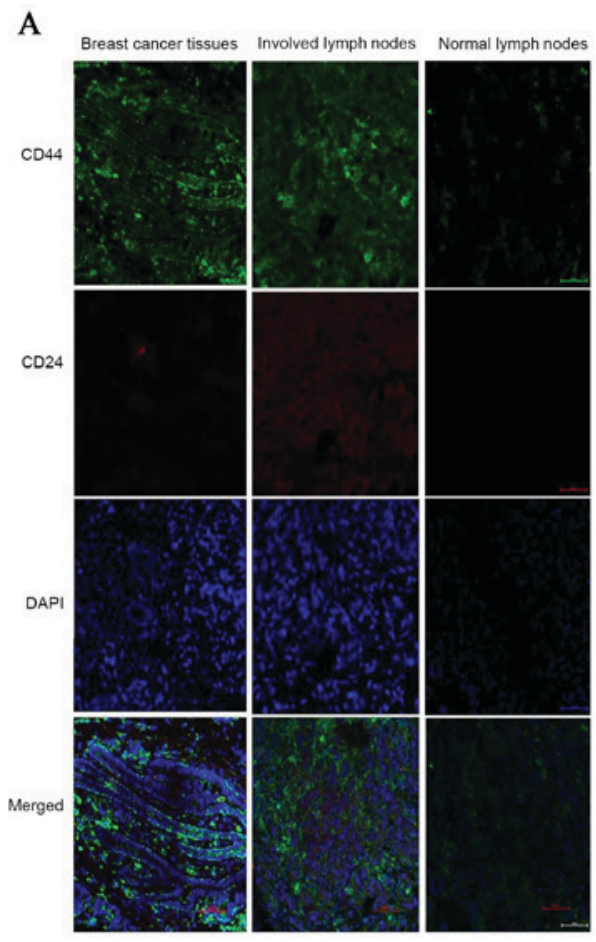

B

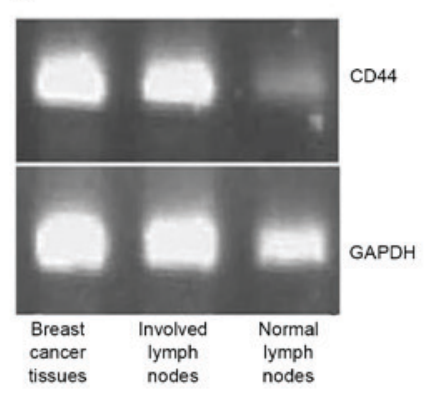

C

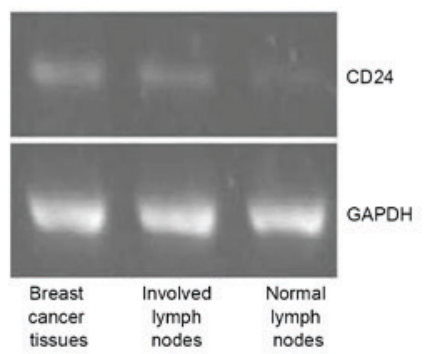

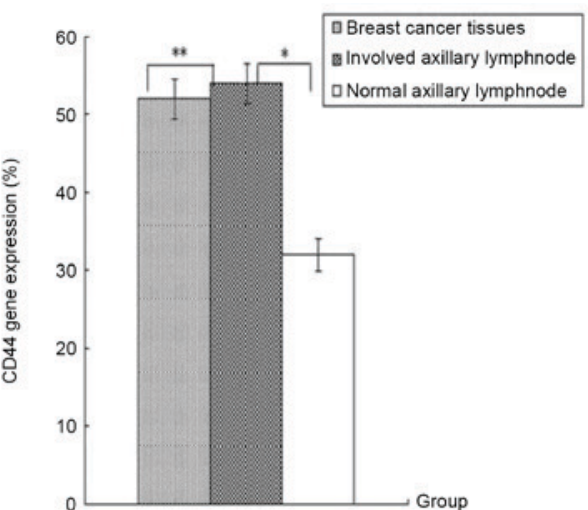

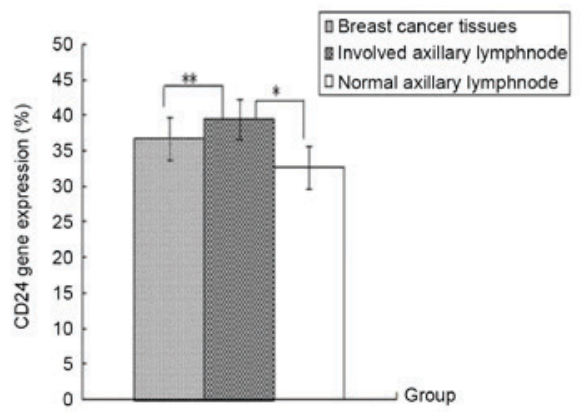

Figure 2. CD44 and CD24 were expressed in the normal or involved ALN and breast cancer tissues, respectively. (A) CD44 and CD24 were expressed at low levels in the normal ALN by immunofluorescence staining and laser confocal microscope analysis. Compared with CD24, CD44 was significantly expressed in the ductal and alveolar lactating epithelium from breast cancer tissues and involved ALN by immunofluorescence staining and laser confocal microscope analysis (green, fluorescein isothiocyanate; red, phycoerythrin R; original magnification, x200; ARIOL automated image analysis system). (B) CD44 mRNA expression was significantly higher in breast cancer tissues and the involved ALN compared with the normal ALN ( $\mathrm{P}<0.05)$ and no statistical difference was observed between the gene expression in breast cancer tissues and the metastatic ALN ( $\left.{ }^{* *} \mathrm{P}>0.05\right)$. (C) CD24 mRNA expression was significantly lower in the three tissues, and the expression levels in the three tissues were not statistically different $\left({ }^{* *} \mathrm{P}>0.05\right)$. CD, cluster of differentiation; ALN, axillary lymph nodes.

more highly expressed compared with CD24 in primary breast cancer tissues and the involved ALN. RT-qPCR analysis for the three tissues demonstrated that CD44 mRNA expression in the breast cancer tissue and the involved ALN was significantly upregulated compared with the normal ALN (Fig. 2B), and no statistical difference was observed between the gene expression in the breast cancer tissues and the metastatic ALN. Conversely, CD24 mRNA expression in the three samples was at low or not detectable levels and no significant difference was observed ( $\mathrm{P}>0.05$; Fig. 2C). The positive expression of CD44 and CD24 is presented in Table II.
ALDH1 overexpression in PT and metastatic ALN. The status of ALDH1 expression in the samples was detected with immunofluorescence staining and RT-qPCR analysis. The immunofluorescence and laser confocal scanning staining (ALDH1 conjugated-FITC) demonstrated that ALDH1 was expressed in the epithelial cytoplasm of the primary breast cancer tissues and the involved ALN; at the same time, it was also weakly expressed in the normal breast gland tissues (Fig. 3A). The positive expression of ALDH1 is presented in Table II. However, the observed densities from the immunofluorescence staining were markedly brighter in the primary breast cancer tissues and metastatic ALN (Fig. 3A) than in 


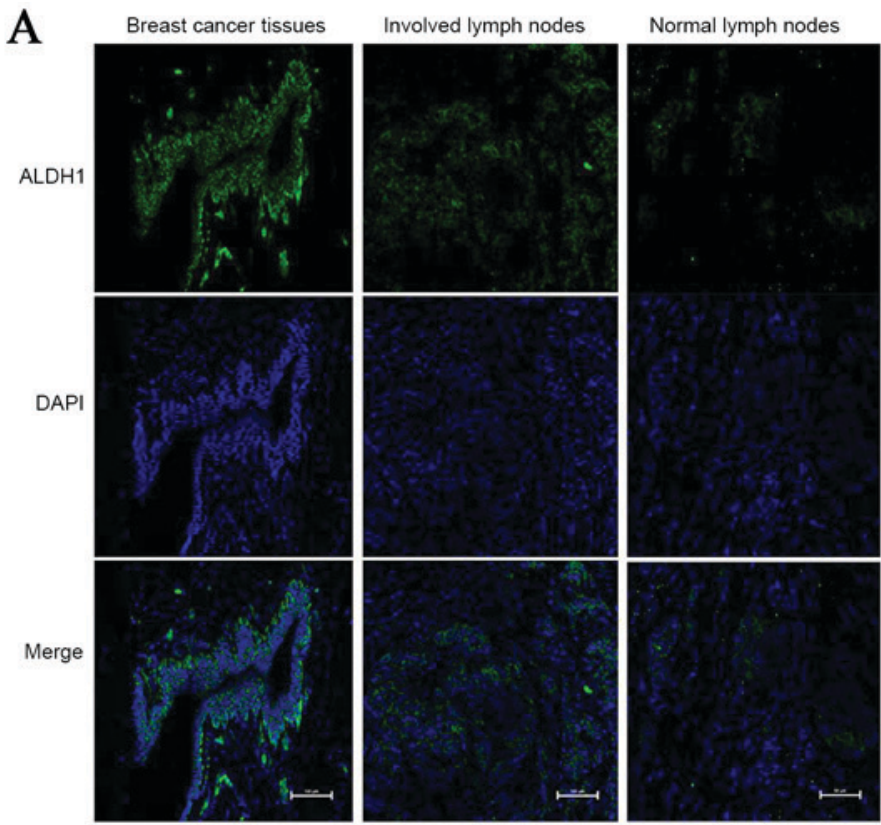

B
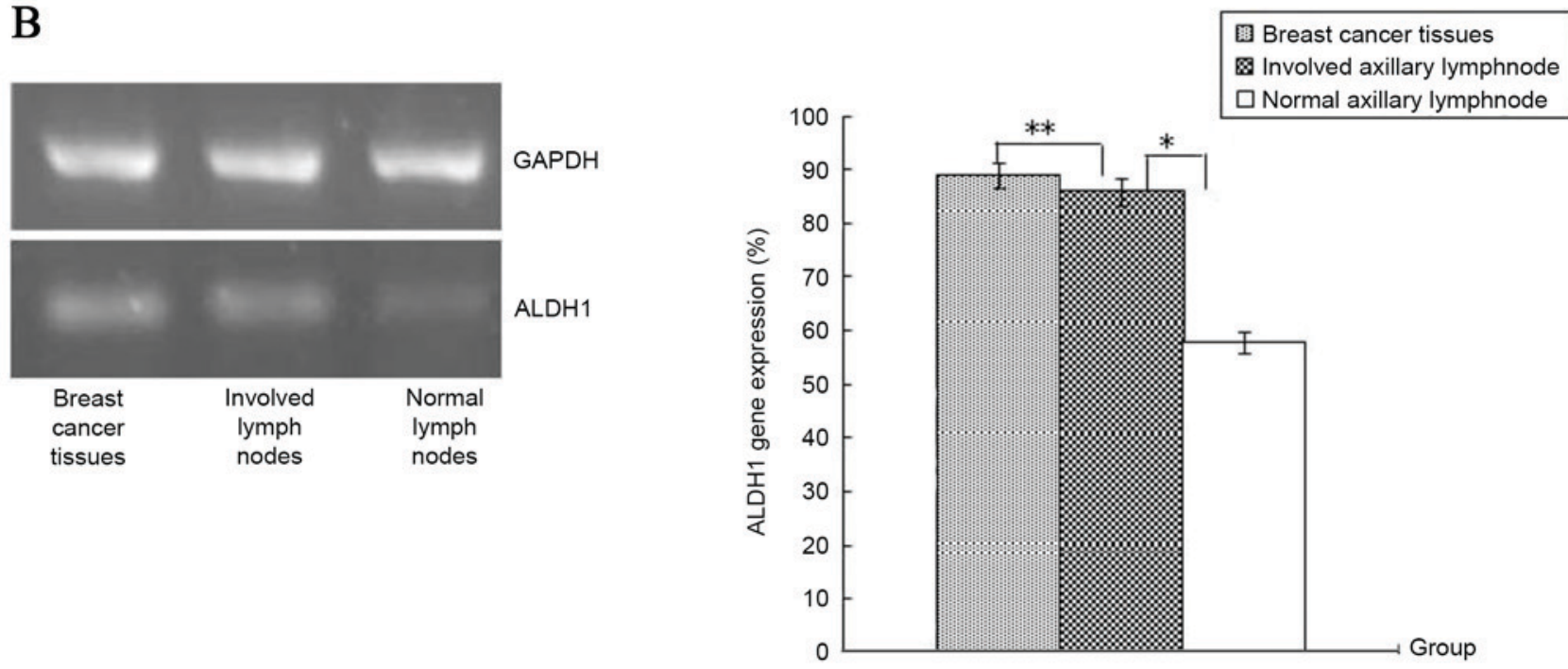

Figure 3. ALDH1 was expressed in the normal or involved ALN and breast cancer tissues. (A) ALDH1 was significantly expressed in the cytosol of tumor cells from the involved ALN compared with normal ALN. ALDH1 was also upregulated in ductal and alveolar lactating epithelium of the primary breast cancer tissues as demonstrated by immunofluorescence staining and laser confocal microscope analysis (green, fluorescein isothiocyanate; original magnification, x200; ARIOL automated image analysis system). (B) ALDH1 mRNA expression was significantly higher in the involved ALN and breast cancer than in the normal ALN ( $\left.{ }^{*} \mathrm{P}<0.05 ;{ }^{* *} \mathrm{P}>0.05\right)$. ALDH, aldehyde dehydrogenase; ALN, axillary lymph nodes.

the normal ALN. Furthermore, the results demonstrated that ALDH1 mRNA expression was significantly higher in the breast cancer and involved ALN than in the normal ALN $(\mathrm{P}<0.05$; Fig. 3B). Furthermore, no statistical difference was observed between the gene expression levels of the breast cancer tissues and the metastatic ALN ( $>>0.05)$.

High expression of Twistl in the PT and metastatic ALN may contribute to the promotion of cancer cell migration, invasion and metastasis. Following immunofluorescence staining and RT-qPCR analysis, the results demonstrated that the Twistl molecule was predominantly localized in the nucleus and cytoplasm of tumor and stromal cells whilst being additionally expressed in normal tissues. However, the observed densities of immunofluorescence staining were markedly weaker in the normal ALN than in the primary breast cancer tissues and metastatic ALN (Fig. 4A; Twist1 conjugated-PE). The positive expression of Twist1 is presented in Table II. In addition, Twist1 mRNA expression was significantly higher in the breast cancer and involved ALN compared with normal ALN ( $\mathrm{P}<0.05$; Fig. 4B). No statistical difference was observed between the gene expression in the breast cancer tissues and the metastatic ALN ( $\mathrm{P}>0.05)$.

E-cadherin, instead of vimentin and $N$-cadherin, was upregulated in metastatic ALN. Following western blotting analysis for primary cancer tissues and the normal and metastatic ALN, the results demonstrated that vimentin (Fig. 5A) expression in primary cancer tissues were significantly higher in the normal and metastatic ALN, and the protein in 
Table III. Association between clinicopathological characteristics and overexpression of CD44, ALDH1, TWIST1 and CA15-3.

\begin{tabular}{|c|c|c|c|c|c|c|c|c|c|c|c|c|}
\hline \multirow[b]{2}{*}{ Variable } & \multicolumn{3}{|c|}{ CD44 overexpression } & \multicolumn{3}{|c|}{ ALDH1 overexpression } & \multicolumn{3}{|c|}{ Twist1 overexpression } & \multicolumn{3}{|c|}{ CA15-3 overexpression } \\
\hline & $\begin{array}{l}\text { Number } \\
\text { of cases }\end{array}$ & $\%$ & P-value & $\begin{array}{l}\text { Number } \\
\text { of cases }\end{array}$ & $\%$ & P-value & $\begin{array}{l}\text { Number } \\
\text { of cases }\end{array}$ & $\%$ & P-value & $\begin{array}{l}\text { Number } \\
\text { of cases }\end{array}$ & $\%$ & P-value \\
\hline \multicolumn{13}{|l|}{ Tumor stage } \\
\hline $\mathrm{T} 1-2$ & $43 / 89$ & 48.3 & & $41 / 78$ & 52.6 & & $39 / 82$ & 47.5 & & $16 / 68$ & 23.5 & \\
\hline T3-4 & $46 / 89$ & 51.7 & 0.327 & $37 / 78$ & 47.4 & 0.342 & $42 / 82$ & 52.5 & 0.168 & $52 / 68$ & 76.5 & 0.031 \\
\hline \multicolumn{13}{|l|}{ Node stage } \\
\hline $\mathrm{N} 1$ & $38 / 84$ & 45.2 & & $41 / 87$ & 47.1 & & $36 / 71$ & 50.7 & & $30 / 68$ & 44.1 & \\
\hline N2- N3 & $46 / 84$ & 54.8 & 0.312 & $46 / 87$ & 52.9 & 0.343 & $35 / 71$ & 49.3 & 0.466 & $38 / 68$ & 55.9 & 0.242 \\
\hline \multicolumn{13}{|l|}{ PR status } \\
\hline Negative & $35 / 79$ & 44.3 & & $24 / 76$ & 31.5 & & $32 / 84$ & 38.1 & & $27 / 68$ & 39.7 & \\
\hline Positive & $44 / 79$ & 55.7 & & $52 / 76$ & 68.5 & & $52 / 84$ & 61.9 & 0.035 & $41 / 68$ & 60.3 & 0.021 \\
\hline \multicolumn{13}{|l|}{ ER status } \\
\hline Negative & $21 / 79$ & 26.5 & & $30 / 81$ & 37.0 & & $32 / 86$ & 37.2 & & $21 / 68$ & 30.9 & \\
\hline Positive & $58 / 79$ & 73.5 & 0.037 & $51 / 81$ & 63.0 & 0.033 & $54 / 86$ & 62.8 & 0.042 & $47 / 68$ & 69.1 & 0.039 \\
\hline \multicolumn{13}{|l|}{ HER2 status } \\
\hline Negative & $63 / 79$ & 79.7 & & $58 / 81$ & 71.6 & & $64 / 86$ & 74.4 & & $48 / 68$ & 70.6 & \\
\hline Positive & $36 / 79$ & 20.3 & & $23 / 81$ & 28.4 & & $22 / 86$ & 25.6 & 0.037 & $20 / 68$ & 29.4 & 0.029 \\
\hline \multicolumn{13}{|l|}{ Histological type } \\
\hline Ductal & $66 / 89$ & 74.2 & & $58 / 81$ & 71.6 & & $66 / 86$ & 76.7 & & $37 / 68$ & 54.4 & \\
\hline Lobular (others) & $23 / 89$ & 25.8 & 0.040 & $23 / 81$ & 28.4 & 0.029 & $20 / 86$ & 23.3 & 0.037 & $31 / 68$ & 45.6 & 0.144 \\
\hline \multicolumn{13}{|l|}{ Family history } \\
\hline Yes & $83 / 89$ & 6.7 & & $11 / 87$ & 12.6 & & $10 / 86$ & 11.6 & & $7 / 68$ & 10.2 & \\
\hline No & $6 / 89$ & 93.3 & 0.043 & $76 / 87$ & 87.4 & 0.039 & $76 / 86$ & 88.4 & 0.035 & $61 / 68$ & 89.8 & 0.046 \\
\hline $\begin{array}{l}\text { Triple-receptor } \\
\text { negative }\end{array}$ & $32 / 89$ & 35.9 & & $19 / 87$ & 21.8 & & $31 / 86$ & 36 & & $20 / 68$ & 29.4 & \\
\hline Others & $57 / 89$ & 64.1 & 0.041 & $68 / 87$ & 78.2 & 0.045 & $55 / 86$ & 64 & 0.042 & $48 / 68$ & 70.6 & 0.059 \\
\hline \multicolumn{13}{|l|}{ Menopausal status } \\
\hline Pre- & $69 / 89$ & 77.5 & & $52 / 87$ & 59.8 & & $58 / 86$ & 67.4 & & $49 / 68$ & 72.1 & \\
\hline Post- & $20 / 89$ & 22.5 & 0.036 & $35 / 87$ & 40.2 & 0.040 & $35 / 87$ & 40.2 & 0.027 & $19 / 68$ & 27.9 & 0.044 \\
\hline
\end{tabular}

CD, cluster of differentiation; ALDH, aldehyde dehydrogenase; CA15-3, carcinoma antigen 15-3; ER, estrogen receptor; PR, progesterone receptor; HER2, human epidermal growth factor receptor 2.

metastatic ALN was increased compared with normal ALN. $\mathrm{N}$-cadherin protein from primary cancer tissues was also highly expressed compared with normal and metastatic ALN (Fig. 5B). Furthermore, the expression of the two markers in primary cancer tissues appeared to be higher compared with the metastatic ALN. This difference was statistically significant $(\mathrm{P}<0.05)$. However, E-cadherin protein expression was higher in metastasized ALN than in primary cancer tissues and in normal ALN $(\mathrm{P}<0.05)$. The difference in E-cadherin expression between the latter two tissues was not statistically significant $(\mathrm{P}>0.05)$.

Although the four genes are all poorly expressed in normal ALN, CD44, ALDH1 and Twist1 are also overexpressed in breast cancer tissues and ALN with the exception of CD24. The expression of the four genes in association with various clinicopathological characteristics is presented in Table II. Table III demonstrates that there was no association between overexpression of these genes (CD44, ALDH1 and Twist1) and tumor stage, nodes stage and family history $(\mathrm{P}>0.05)$. A more significant association lay between the overexpression of these genes and PR, ER, triple-receptor negative and HER2/neu status. Patients whose receptors were positive were more likely to have an overexpression of CD44, ALDH1 and Twist1 $(\mathrm{P}<0.05)$. The proportion of CD44, ALDH1, Twist1 and CA15-3 overexpression was also increased in the patients with triple-receptor negative or pre-menopausal breast cancer.

Serum CA15-3 levels can be used to evaluate the clinical pathological stage of the tumor. The serum levels of the carbohydrate antigen CA15-3 in the patients' blood was tested on the fourth day prior to surgery and the third day following surgery. The results demonstrated that the serum CA15-3 levels of patients in stages I and II $(39.9 \pm 11.6)$ were significantly 

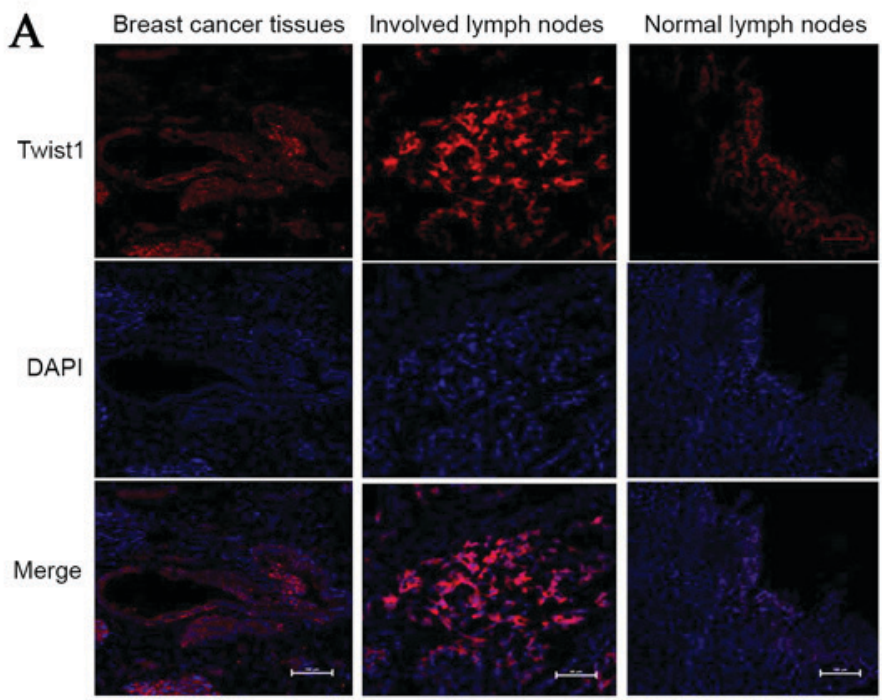

B
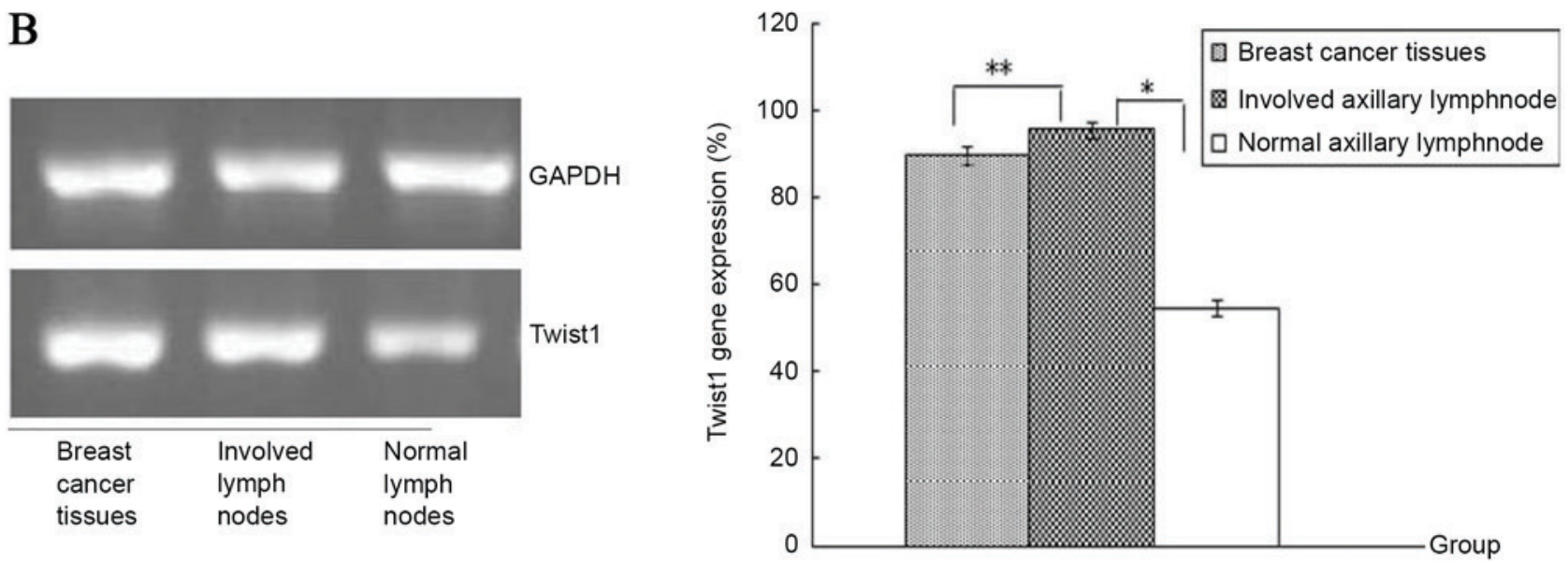

Figure 4. Twist1 was detected in the involved or normal ALN and breast cancer tissues. (A) Twist1 was predominantly expressed in the nucleus and cytosol of cancer cells and to a lesser extent in the stromal tissue and normal breast tissue. However, Twistl intensity was lower in the normal ALN than in the involved ALN and breast cancer tissues as demonstrated by immunofluorescence and laser confocal microscope analysis (red, phycoerythrin R; original magnification, x200; ARIOL automated image analysis system). (B) Twist1 mRNA expression was significantly higher in the breast cancer and involved ALN than in the normal ALN $\left({ }^{*} \mathrm{P}<0.05\right)$. No statistical difference was observed between the gene expression in breast cancer tissues and involved ALN $\left.{ }^{* * *} \mathrm{P}>0.05\right)$. ALN, axillary lymph nodes.

Table IV. Serum levels of CA15-3 from the enrolled patients with primary breast cancer in four groups.

\begin{tabular}{lccc}
\hline & \multicolumn{3}{c}{ Serum CA15-3 (level $>39 \mathrm{U} / \mathrm{ml})$} \\
\cline { 2 - 4 } Variable & $\begin{array}{c}\mathrm{U}(\text { mean } \pm \text { standard } \\
\text { deviation) }\end{array}$ & $\mathrm{n}$ & $\%$ \\
\hline Pre-operation & $65.8 \pm 21.6$ & $68 / 102$ & 66.7 \\
Post-operation & $67.9 \pm 17.3$ & $56 / 102$ & 54.9 \\
Stage I-II & $39.9 \pm 11.6$ & $21 / 102$ & 20.5 \\
Stage III-IV & $78.4 \pm 18.1$ & $47 / 102$ & 79.5 \\
\hline
\end{tabular}

$\mathrm{P}>0.05$ pre-operation vs. post-operation; $\mathrm{P}<0.05$ Stage I-II vs. Stage III-IV. CA15-3, carcinoma antigen 15-3.

lower compared with stages III and IV $(78.4 \pm 18.1 ; \mathrm{P}<0.05)$. However, no statistical difference was observed between the pre-operative $(65.8 \pm 21.6)$ and the post-operative blood testing $(67.9 \pm 17.3, \mathrm{P}>0.05$; Table IV).
Survival analysis. The median PFS for the patients was 4 years and 194 days, that for $\mathrm{CD} 44^{+} \mathrm{CD} 24 \%$ ALDH1/Twist1 ${ }^{-}$was 5 years and 252 days and that for $\mathrm{CD}_{4} 4^{+} \mathrm{CD} 24^{-} / \mathrm{ALDH}^{+} / \mathrm{Twist}^{+}$was 4 years and 184 days. $\mathrm{CD} 44^{+} \mathrm{CD} 24^{-} / \mathrm{ALDH} 1^{+} / \mathrm{Tw}$ ist $1^{+} / \mathrm{CA} 153^{\text {high }}$ was 2 years and 263 days whereas $\mathrm{CD} 44^{+} \mathrm{CD} 24^{-} / \mathrm{ALDH}^{-} / \mathrm{Tw}^{-}$ist $^{-} \mathrm{CA} 153^{\text {low }}$ was 6 years and 169 days $(\mathrm{P}<0.05)$. No significant difference in median survival was observed between $\mathrm{CD} 44^{+} \mathrm{CD} 24$ cancers and the other groups $(\mathrm{P}<0.05)$. By analyzing the prognosis of the patients with hormone receptor and HER2-negative tumors $(n=52)$, statistically significant differences were observed in hormone receptor tumors. The median PFS of HER2-negative was shorter than HER2-positive $(\mathrm{P}<0.05)$.

The univariate and binary logistic regression analysis on 102 cases was used to assess the associations between tumor markers and clinical characteristics. The combining status of $\mathrm{CD} 44^{+} \mathrm{CD} 24^{-} / \mathrm{ALDH} 1^{+} / \mathrm{Tw}$ ist $1^{+} / \mathrm{CA} 15-3^{+}$and triple-receptor negative were all significant factors strongly associated with worseprognosis $(\mathrm{P}=0.018)$. Notably,only the presence of membranous $\mathrm{CD}^{-} 4^{+} \mathrm{CD} 24^{-}$or $\mathrm{CD} 44^{-} \mathrm{CD} 24^{-/ A L D H 1} /$ Twist1 $^{-} \mathrm{CA} 153^{\text {low }}$ 
A

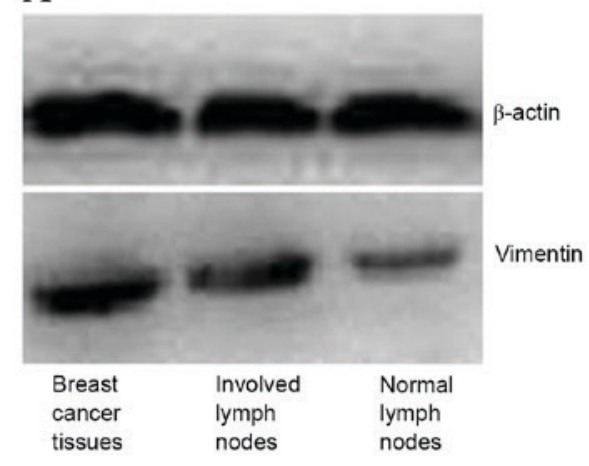

B

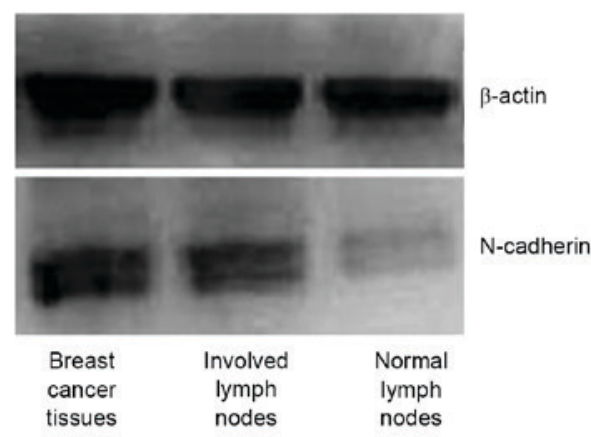

$\mathrm{C}$

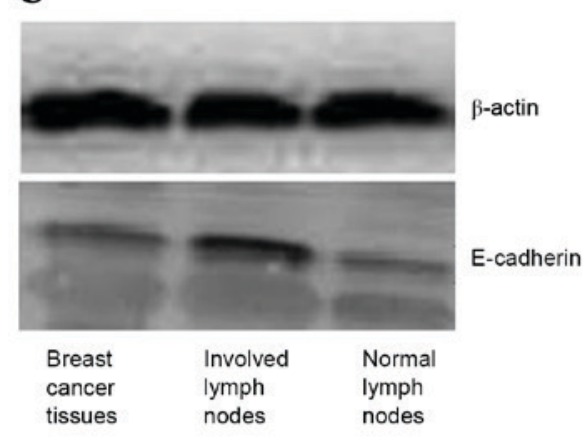

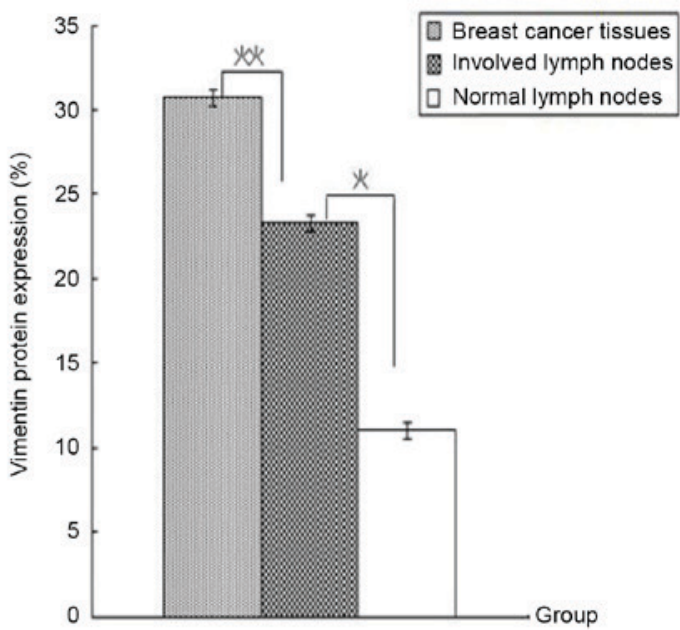
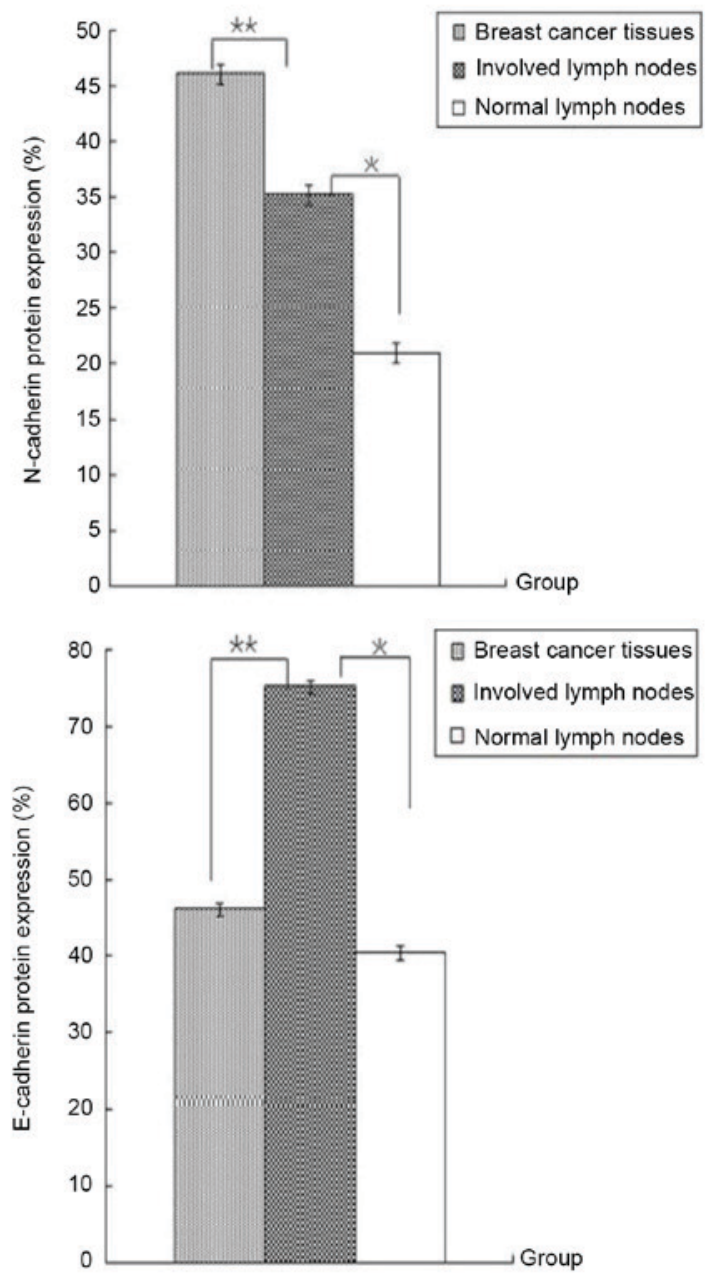

Figure 5. EMT markers were evaluated in the normal and metastatic ALN and breast cancer tissues. Western blotting analysis demonstrated (A) vimentin expression in primary cancer tissues was significantly higher in the normal and metastatic ALN, and the protein in metastatic ALN was increased compared with normal ALN. (B) N-cadherin protein from primary cancer tissues was also highly expressed compared with the normal and metastatic ALN. The expression of the two markers in primary cancer tissues appeared to be higher compared with metastatic ALN. This difference was statistically significant ("P $<0.05)$. (C) E-cadherin protein expression was higher in involved ALN than in primary cancer tissues and in normal ALN ( $\left.\mathrm{P}<0.05 ;{ }^{* *} \mathrm{P}>0.05\right)$. The comparison of E-cadherin expression between the latter two tissues was statistically significant. EMT, epithelial-mesenchymal transition; ALN, axillary lymph nodes.

resulted in a favorable prognostic factor $(\mathrm{P}=0.003$ and $\mathrm{P}=0.021$, respectively; Table V). Subsequent to an evaluation of the prognostic relevance of the significant univariate parameters, a multivariate logistic regression analysis also indicated that poor prognosis correlated with the tumor markers demonstrated in the Kaplan-Meier breast cancer survival curves, which illustrated the decreasing survival associated with overexpression of genes (Fig. 6). 
Table V. Multivariate logistic regression analysis for tumor markers predicting prognosis of 102 patients with breast cancer.

\begin{tabular}{|c|c|c|}
\hline Variable & Hazard ratio $95 \% \mathrm{CI}$ & P-value \\
\hline $\mathrm{CD}_{4} 4^{+} \mathrm{CD} 24 / \mathrm{ALDH}^{-} / \mathrm{TWIST}^{-}$ & $2.9237 .010-9.246$ & 0.022 \\
\hline $\mathrm{CD}_{4}{ }^{-\mathrm{CD}} 24^{-} / \mathrm{ALDH}^{+}{ }^{+} / \mathrm{TWIST}^{+}{ }^{+}$ & $5.2144 .160-6.994$ & 0.040 \\
\hline $\mathrm{CD} 44^{+} \mathrm{CD} 24-\mathrm{TWIST}^{-} / \mathrm{CA} 15-3^{-}$ & $3.1855 .624-9.540$ & 0.031 \\
\hline $\mathrm{CD} 44^{+} \mathrm{CD} 24-\mathrm{TWIST}^{+} / \mathrm{CA} 15-3^{+}$ & $7.1536 .122-9.532$ & 0.038 \\
\hline HER2-negative/TWIST1/CA15-3- & $1.8314 .152-9.334$ & 0.033 \\
\hline HER2-positive/TWIST1+/CA15-3+ ${ }^{+}$ & $7.0635 .120-9.630$ & 0.029 \\
\hline Triple-receptor negative/TWIST1^/CA15-3- & $4.0286 .187-9.925$ & 0.048 \\
\hline Triple-receptor negative/TWIST1 ${ }^{+} / \mathrm{CA} 15-3^{+}$ & $8.0644 .112-8.530$ & 0.021 \\
\hline
\end{tabular}

CI, confidence interval; CD, cluster of differentiation; ALDH, aldehyde dehydrogenase; CA15-3, carcinoma antigen 15-3; HER2, human epidermal growth factor receptor 2 .

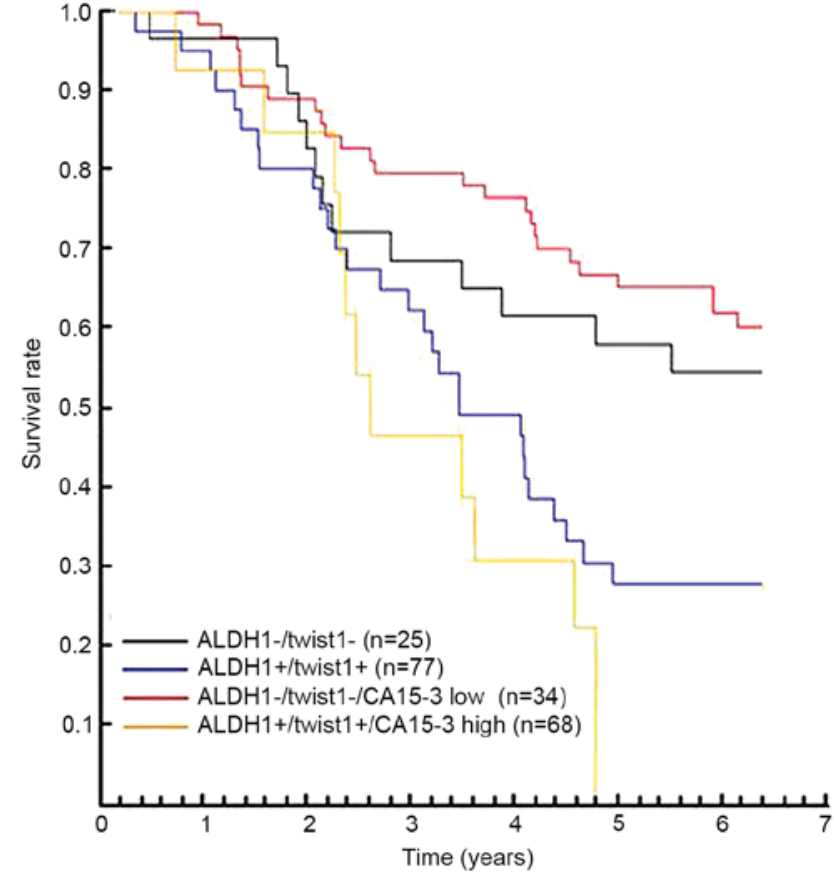

Figure6.Breastcancersurvivalratecurves.Kaplan-Meierbreastcancersurvival rate curves for the overexpression of genes in tumor and ALN tissues among a population-based cohort of patients with primary invasive breast cancer who underwent surgery between 2007-2014 and were followed-up for $>6$ years (red folding line, $\mathrm{CD} 44^{+} \mathrm{CD} 24^{-} / \mathrm{ALDH1} /{ }^{-} /$Twist $^{-} \mathrm{CA} 153^{\text {low; }}$; black folding line,

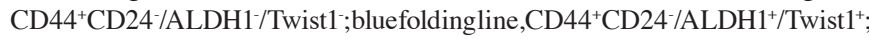
and yellow folding line, $\left.\mathrm{CD} 44^{+} \mathrm{CD} 24 / \mathrm{ALDH1}^{+} / \mathrm{Twist}^{+} / \mathrm{CA} 153^{\text {high }}\right)$. ALN, axillary lymph nodes; $\mathrm{CD}$, cluster of differentiation; ALDH, aldehyde dehydrogenase; CA15-3, carcinoma antigen 15-3.

\section{Discussion}

BCSCs expressing the $\mathrm{CD} 44^{+} \mathrm{CD} 24^{-/ \mathrm{llow}}$ molecular phenotype additionally possess numerous properties including self-renewal, proliferation and the ability to promote the metastasis of tumor cells (18). Hallmarks of these tumors include a high enrichment for a $\mathrm{CD} 44^{+} / \mathrm{CD} 24^{-/ \text {low }}$ tumor-initiating cell signature, the downregulation of cell junction proteins including cadherins and claudins, an enrichment of mesenchymal markers, high lymphocyte infiltration and high phenotypic resistance to chemotherapy $(19,20)$. ALDH1 $1^{+}$

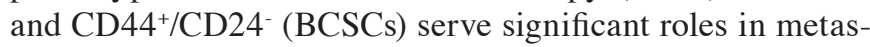
tasis (21). The results of the present study confirmed that CD44 and ALDH1 were only poorly expressed in normal breast tissues but highly expressed in tumor tissues and involved ALN. However, CD24 expression was negative or low in the above three tissues, consistent with previous studies. In addition, the results indicated that CD44 and ALDH1 may serve a key role in introducing tumorigenesis and then maintaining their expression with no apparent changes. ALDH1 confers a tumorigenic character when expressed at levels higher than the normal range. High expression of ALDH1 has been associated with good overall survival $(\mathrm{P}=0.021)(22)$, however, the results of the present study demonstrated that high ALDH1 expression was involved in disease recurrence or poor survival rates. The rate of $\mathrm{ALDH} 1^{+}$cells appears to be an improved predictive marker of breast cancer metastasis than the $\mathrm{CD} 44^{+} / \mathrm{CD} 24^{-}$phenotype (21). Twist1 overexpression in breast cells can promote the generation of a BCSC phenotype characterized by the high expression of CD44, little or no expression of CD24 and increased ALDH1 activity, independent of the EMT $(23,24)$. The induction of EMT enables epithelial cells to acquire the properties of mesenchymal lineages, including enhanced mobility and invasiveness, which are closely correlated with cancer metastasis $(25,26)$. The well-defined features of EMT include the loss of epithelial markers (E-cadherin and $\alpha$ - and $\gamma$-catenin), the gain of mesenchymal cell markers (fibronectin, vimentin and $\mathrm{N}$-cadherin), and the acquisition of migratory and invasive properties (27). The results of the present study demonstrated that Twist1 mRNA was significantly higher in breast cancer and involved ALN than in the normal ALN. As EMT markers, $\mathrm{N}$-cadherin and vimentin proteins of the involved ALN were poorly expressed compared with breast cancer tissues, but E-cadherin protein expression was higher in metastasized and normal ALN compared with primary cancer tissues. This may suggest that Twist1 overexpression is correlated with the easy migration of tumors or a shorter PFS. The high expression of Twist1 and SNAIL in LNM and the negative-to-positive conversion of SNAIL confer worse prognosis, thus confirming the correlation of EMT with aggressive disease behavior (11). The results of the present 
study demonstrated that all Twist1-high samples, including the involved ALN compared with the normal ALN, exhibited low ER and PR levels and high HER2 levels, which may indicate that Twist1 and ER or PR are inversely correlated in breast cancer patients. Chromatin immunoprecipitation and promoter assays demonstrated that Twist could directly bind to E-boxes in the ER promoter and significantly downregulate ER promoter activity in vitro (28). The low expression of ER and high expression of Twist1 in breast tumors correlated with increased tumor recurrence and metastasis and poor progression-free survival. CA15-3 has been considered a representative tumor marker for breast cancer (7). The results of the present study demonstrated that the serum levels of CA15-3 are not statistically different in the pre-operative and post-operative states. However, CA15-3 levels were significantly upregulated in advanced cancer compared with early stage cancer, which suggested that the change of CA15-3 levels was not associated with surgical resection however with the stage of cancer. High serum levels of tumor markers and high expression of Twist1 may suggest an increased likelihood of relapse and a poor prognosis. The results of the present study also demonstrated that Twist $1^{+} / \mathrm{CA} 15-3^{+}$, HER2-negative/Twist $1^{+} / \mathrm{CA} 15-3^{+}$and triple-receptor negative/Twist $1^{+} / \mathrm{CA} 15-3^{+}$groups displayed a worse prognosis compared with the others, suggesting that the assays can be widely used for monitoring disease progression and response to therapy in some patients with late stage breast cancer. CEA (6) and BCA225 (29) are also considered useful tumor markers, alone and in combination with CA15-3, for detecting the recurrence of breast cancer. Although they have some shortcomings, they are particularly valuable for monitoring treatment in patients who have diseases that cannot be evaluated by radiology (30).

In conclusion, the results of the present study demonstrated that CD44, ALDH1 and Twist1 were significantly overexpressed in primary cancer tissues and involved ALN while the serum levels of CA15-3 of those patients were markedly increased and survival rates fell, which suggests that patients, in particular those with advanced cancer, may have a poor prognosis. Note that the present study did not specifically engage in the underlying mechanism of how the aforementioned genes are correlated with poor prognosis or chemotherapy; that remains to be elucidated.

\section{Acknowledgements}

The present study was supported by the Natural Science Foundation of Chongqing, China (grant no. cstc2011jjA0058). The authors would like to thank the staff of the Department of Breast Gland Surgery and Department of Clinical Pathology, The Second Affiliated Hospital of Chongqing Medical University for their technical assistance, and the study participants for donating the samples. The authors thank Professor Zhangxiong of Chongqing Medical University (Chongqing, China) for critical technical assistance.

\section{References}

1. Velasco-Velázquez MA, Homsi N, De La Fuente M and Pestell RG: Breast cancer stem cells. Int J Biochem Cell Biol 44: 573-577, 2012.
2. Vazquez-Martin A, Oliveras-Ferraros C, Cufí S, Del Barco S, Martin-Castillo B and Menendez JA: Metformin regulates breast cancer stem cell ontogeny by transcriptional regulation of the epithelial-mesenchymal transition (EMT) status. Cell Cycle 9: 3807-3814, 2010.

3. Ginestier C, Hur MH, Charafe-Jauffret E, Monville F, Dutcher J, Brown M, Jacquemier J, Viens P, Kleer CG, Liu S, et al: ALDH1 is a marker of normal and malignant human mammary stem cells and a predictor of poor clinical outcome. Cell Stem Cell 1: 555-567, 2007.

4. Li J and Zhou BP: Activation of $\beta$-catenin and Akt pathways by Twist are critical for the maintenance of EMT associated cancer stem cell-like characters. BMC Cancer 11: 49, 2011.

5. Ru GQ, Wang HJ, Xu WJ and Zhao ZS: Upregulation of twist in gastric carcinoma associated with tumor invasion and poor prognosis. Pathol Oncol Res 17: 341-347, 2011.

6. Li S, Kendall SE, Raices R, Finlay J, Covarrubias M, Liu Z, Lowe G, Lin YH, Teh YH, Leigh V, et al: TWIST1 associates with NF- $\kappa B$ subunit RELA via carboxyl-terminal WR domain to promote cell autonomous invasion through IL8 production. BMC Biol 10: 73, 2012.

7. Kong Y, Wang J, Liu W, Chen Q, Yang J, Wei W, Wu M, Yang L, Xie X, Lv N, et al: Cytokeratin19-2g2, a novel fragment of cytokeratin19 in serum, indicating a more invasive behavior and worse prognosis in breast cancer patients. PLoS One 8: e57092, 2013.

8. Eckert MA,Lwin TM, Chang AT, Kim J,Danis E, Ohno-Machado L and Yang J: Twist1-induced invadopodia formation promotes tumor metastasis. Cancer Cell 19: 372-386, 2011.

9. Qin Q, Xu Y, He T, Qin C and Xu J: Normal and disease-related biological functions of Twistl and underlying molecular mechanisms. Cell Res 22: 90-106, 2012.

10. Sleeman JP, Cady B and Pantel K: The connectivity of lymphogenous and hematogenous tumor cell dissemination: Biological insights and clinical implications. Clin Exp Metastasis 29: 737-746, 2012.

11. Markiewicz A, Ahrends T, Wełnicka-Jaśkiewicz M, Seroczyńska B, Skokowski J, Jaśkiewicz J, Szade J, Biernat W and Zaczek AJ: Expression of epithelial to mesenchymal transition-related markers in lymph node metastases as a surrogate for primary tumor metastatic potential in breast cancer. J Transl Med 10: 226, 2012.

12. Sell S: Cancer-associated carbohydrates identified by monoclonal antibodies. Hum Pathol 21: 1003-1019, 1990.

13. Hilkens J, Buijs F, Hilgers J, Hageman P, Calafat J, Sonnenberg A and van der Valk M: Monoclonal antibodies against human milk-fat globule membranes detecting differentiation antigens of the mammary gland and its tumors. Int J Cancer 34: 197-206, 1984.

14. Duffy MJ, Evoy D and McDermott EW: CA 15-3: Uses and limitation as a biomarker for breast cancer. Clin Chim Acta 411: 1869-1874, 2010

15. Zhou J, Zhang L, Gu Y, Li K, Nie Y, Fan D and Feng Y: Dynamic expression of CEACAM7 in precursor lesions of gastric carcinoma and its prognostic value in combination with CEA. World J Surg Oncol 9: 172, 2011.

16. Sobin LH, Hermanek P and Hutter RV: TNM classification of malignant tumors. A comparison between the new (1987) and the old editions. Cancer 61: 2310-2314, 1988.

17. Elston CW and Ellis IO: Pathological prognostic factors in breast cancer. I. The value of histological grade in breast cancer: Experience from a large study with long-term follow-up. Histopathology 19: 403-410, 1991.

18. Montgomery N, Hill A, McFarlane S, Neisen J, O'Grady A, Conlon S, Jirstrom K, Kay EW and Waugh DJ: CD44 enhances invasion of basal-like breast cancer cells by upregulating serine protease and collagen-degrading enzymatic expression and activity. Breast Cancer Res 14: R84, 2012.

19. Prat A, Parker JS, Karginova O, Fan C, Livasy C, Herschkowitz JI, He X and Perou CM: Phenotypic and molecular characterization of the claudin-low intrinsic subtype of breast cancer. Breast Cancer Res 12: R68, 2010.

20. Creighton CJ, Li X, Landis M, Dixon JM, Neumeister VM, Sjolund A, Rimm DL, Wong $\mathrm{H}$, Rodriguez A, Herschkowitz JI, et al: Residual breast cancers after conventional therapy display mesenchymal as well as tumor-initiating features. Proc Natl Acad Sci USA 106: 13820-13825, 2009.

21. Zhong Y, Shen S, Zhou Y, Mao F, Guan J, Lin Y, Xu Y and Sun Q: ALDH1 is a better clinical indicator for relapse of invasive ductal breast cancer than the CD44+/CD24- phenotype. Med Oncol 31: 864, 2014. 
22. Sung WJ, Park KS, Kwak SG, Hyun DS, Jang JS and Park KK Epithelial-mesenchymal transition in patients of pulmonary adenocarcinoma: Correlation with cancer stem cell markers and prognosis. Int J Clin Exp Pathol 8: 8997-9009, 2015.

23. Vesuna F, Lisok A, Kimble B and Raman V: Twist modulates breast cancer stem cells by transcriptional. Neoplasia 11: 1318-1328, 2009

24. Li J and Zhou BP: Activation of $\beta$-catenin and Akt pathways by Twist are critical for the maintenance of EMT associated cancer stem cell-like characters. BMC Cancer 11: 49, 2011.

25. Kalluri R: EMT: When epithelial cells decide to become mesenchymal-like cells. J Clin Invest 119: 1417-1419, 2009.

26. Chaffer CL and Weinberg RA: A perspective on cancer cell metastasis. Science 331: 1559-1564, 2011.

27. Huber MA, Kraut N and Beug H: Molecular requirements for epithelial-mesenchymal transition during tumor progression. Curr Opin Cell Biol 17: 548-558, 2005.
28. Vesuna F, Lisok A, Kimble B, Domek J, Kato Y, vander Groep P, Artemov D, Kowalski J, Carraway H, van Diest P and Raman V: Twist contributes to hormone resistance in breast cancer by downregulating estrogen receptor- $\alpha$. Oncogene 31: 3223-3234, 2012.

29. Ri G, Ohno S, Yamamoto T, Ito E, Furutani M, Furutani Y, Umeda Y, Tsukahara T, Hagita N and Matsuoka R: Serum levels of CA15-3, KL-6 and BCA225 are positively correlated with each other in the general population. Anticancer Res 29: 4239-4242, 2009.

30. Bidard FC, Hajage D, Bachelot T, Delaloge S, Brain E, Campone M, Cottu P, Beuzeboc P, Rolland E, Mathiot C and Pierga JY: Assessment of circulating tumor cells and serum markers for progression-free survival prediction in metastatic breast cancer: A prospective observational study. Breast Cancer Res 14: R29, 2012 